\title{
Comparative mobilities in an unequal world: researching intersections of gender and generation
}

Lesley Murray, Kim Sawchuk and Paola Jirón

Lesley Murray, University of Brighton, UK, L.Murray@brighton.ac.uk

Kim Sawchuk, Concordia University, Canada, kim.sawchuk@sympatico.ca

Paola Jirón, University of Chile, Chile, paolajirón@uchilefau.cl

\begin{abstract}
Mobilities are shaped by social inequalities and spatial unevenness as demonstrated in a range of existing studies across disciplines. These inequalities are manifest at different scales, from the very local spaces of everyday life to global spaces of accelerated mobilities. Mobile spaces, however distant, are connected through common everyday practices and the socio-cultural contexts in which they are produced. In this paper we argue that researching these interconnectivities and commonalities requires a particular methodological approach that accounts for the situatedness of experience. Our focus is on the ways in which inequalities according to gender and generation are generated through urban designed spaces. We suggest that drawing in to a shared material and 'border' object, the urban bench, provides a point of reflection on these distant yet parallel expressions of mobile inequality.
\end{abstract}

Keywords

Gender, generation, urban borders, bench study, comparative mobilities

Introduction

It is a brisk mid winter afternoon in Santiago, Chile. At the Centro Cultural Gabriela Mistral (GAM), a cultural space just off a main street in the city centre, an older woman has been sitting, knitting, on one of the space's wooden benches for hours, despite the cold. She says that she is ok as she has a thermos of tea. She is waiting for her teenage grandchildren who come to this public space to dance every Saturday. They depend on her being there as they would not be able to come downtown and dance in the space unaccompanied. The space is open on two sides with a roof, so it is sheltered. The bench affords her presence. She is able to sit without feeling like she is bothering anyone and observe all the comings and goings of the day. Meanwhile, in Montreal's Shamrock Place, it is already hot on this summer day. An older gentleman sits on one of the coveted swinging seats that is in the shade, situated just in front of a carousel. His Walkman is on the table top in front of him. Music in his ears, he gently rocks back and forth enjoying the sight of children jumping on and off of the carousel, and the bustle of shoppers toting bags of fresh produce from the local market. On a similar day in Jubilee Square, Brighton, UK, in a similar site of cultural significance, these acts of passive repose on a public bench are less apparent. The sculptural bench, 'Liquidus', is an artwork, commissioned by the local authority as part of a policy to promote public art. Constructed of wood and acrylic slices, the bench has fallen into disrepair as its artwork status positions it outside the remit of the private company that manages the space. The wood has eroded leaving uncomfortable acrylic barbs as the most prominent means of support for those using it. It is hence used, or not used, discerningly, noticeably by more men than women and by more younger people than older people. In these three cites, the mobilities of an urban bench are thus interwoven with gendered and (inter)generational mobilities, which are produced through its politics, materiality and location. They are sites to reflect on the uneven and unequal mobilities in cities across the world.

A bench may seem a strange object to consider as the ethnographic focus for a comparative study of gendered and generational mobilities. Benches, particularly those in public spaces, typically do not move - at least of their own 
accord. Yet benches, in their relative simplicity, are mutable objects with multiple affordances. They are 'boundary objects' (Star 1989, 2010) that allow flexibility of mobile practices and therefore act as 'territorial edges', spaces in which social mixing becomes possible and the city is 'open' to difference (Sennett 2006). A bench may be a place to practice a skateboard trick, to meet friends outside of the home, to feed a hungry child, to sleep, or to just sit. Each and every bench is located somewhere, has a particular design, and may act as a potential meeting ground for bodies seeking a temporary moment of respite or momentary stillness. Benches are related not only to the identities and activities of their potential users but to their locations. (In Chile, for example, wooden benches are seen as a source of firewood and therefore are rare in low income areas.) In this paper, we take the bench as a point of comparative reflection on the entanglements of gendered and generational mobilities across three cities: Montreal, Canada, Santiago, Chile, and Brighton UK. We live in these cities and we each have spent time in three particular locations where benches have been placed in street spaces that have been redesigned: in Brighton Jubilee Square, in Montreal Shamrock Place, and GAM, in Santiago. These redesigns have altered the relationship between the bench, the pavement (sidewalk) and the street, re-patterning the movements through these spaces. Underlying our reflections is a collaborative research project that is a comparative study of the ways in which street spaces are mediated by technologies and design, such as the creation of kerb cuts to create access, the elimination of kerbs, road signs and signals, the introduction of flower pots; and benches that not only shape mobility patterns, including gendered and generational encounters. In this study gender and generations collide and co-exist in patterns of movements that create alternative street hierarchies or street practices that become interwoven through the embodied movements. As Bostock (2000) has written experience of a street is distinct if one drives through it on bike, car, or motorized scooter or navigates it on foot by wheeling a walker, hauling a cart of groceries, or shepherding children. These are examples of the embodied encounters of gender and generation. Reliance on others - grandparents, siblings, extended family, friends, social networks makes possible and shapes particular mobilities (Jirón and Imilan 2014; Jirón and Iturra 2014). A comparison of these spaces mediated by benches is a way to think about the intersections between gender and generation as well as what it means to do comparative mobilities that is attentive to differential relations of power and resources within a global context. This article is therefore a call for mobile methodologies that are attentive to those who experience unequal mobilities within urban space.

\section{Gendered and generational mobilities}

Gendered mobilities have been the focus of a number of recent studies of migration (Walsh et al. 2013; Yeoh and Ramdas 2014) and development policies in the Global South (Akyelken 2013; Gutiérrez, 2011), however gender is not always rendered visible in studies that focus on everyday mobilities. By everyday mobilities we mean those movements at a local level tied to the routines and practices associated with everyday life at a local level: shopping for groceries, travel to and from places of work, trips to school, the doctor, the hospitals, alone or with others. While the concept of everyday life has been a key one in mobilities studies, there have been few explicit publications on the junction of gender and mobilities since Priya Uteng and Cresswell's 2008 collection, Gendered Mobilities. Nonetheless, the concept of the everyday in relationship to mobilities is inextricably tied to questions of gender and the ways in which gender roles influence our routines and practices throughout a day. Walsh et al. $(2013,261)$ argue that an understanding of mobilities 'requires analysing women and men as gendered actors across a variety of scales'. The concept of the everyday brings us back to questions of scale, including the scale of the city where more focus and attention empirically, theoretically and methodologically is needed. Here, we question how mobilities scholars might be more attentive to gender and the ways in which mobilities and urban space are co-produced. And if we are concerned with local levels, and everyday routines, how might we unravel the other dimensions including economic, cultural, racialised or age-related differences that may intersect with gender and produce differential forms of mobility and or unequal mobilities? Similarly, in studies of age and mobilities (Delbosc 2012; Nordbakke and Schwanen 2014), it is clear that the different approaches taken do not necessarily engage with a much-needed intersectional analysis of gendered and generational mobilities (Murray 2015a).

Nevertheless, researchers on age and ageing including Zeigler and Schwanen (2011) have engaged in exploratory studies of ageing, mobility and well-being within the context of Durham County, England underscoring the import of understanding mobility as more than physical movement through space, but as well as a disposition for movement. Using methods associated with the work of Erving Goffman, Christian Fisker has suggested that we study the mobility patterns and habits of older adults - developing the concept of 'gerontomobilities' as a way to 
think through the intersection of ageing studies and mobilities studies, particularly germane with demographic transformations of populations world-wide. Likewise in their work on older adults use of mobile technologies, Crow and Sawchuk (2012) discuss the performative aspects of cell phone use by older adults within public space, in Canada, as it is related to physical mobility and other constraints including the need to consider safety while driving or leaving the home because of the possibility of encountering dangerous weather systems. It is research that pays attention to the different mobility practices tied to understandings of the role of grandparents in relationship to children, as well as the continuation of different media practices and "literacies" as they are related to one's work life before and after retirement. This work on ageing, mobilities and technology brings us back to questions not only of gender, but generation. In her recent work on generational mobilities Murray (2015a) draws from Mannheim's conceptualisation of 'generation' as more than 'the product of biology.' Hence generation is associated with a 'location' and is best understood as a continuum where members of a group become associated to each other through shared experiences within a particular socio-political and historical context. Members of a generation may come to inhabit the same social space but may acquire different senses of their identity, and sense of belonging that depends on their accumulated experiences or histories of mobilities.

Embodied encounters of gender and generation intersect on a daily basis and evolve as the life cycle evolves, as do mobility practices. These intersections are relevant because they allow us to observe time space as scales of action that, due to contemporary mobility practices, are in constant shift as they at times may appear very local, but can sometimes be simultaneously local and global, through the use of technology and increasing interdependent relations. These intersections and interdependencies are experienced locally but produced at wider scales - through political discourse and material cultures, for example, particular cultures of mothering produce particular embodied and material practices that may be associated, for example with the pushchair's global branding (Cortés-Morales and Christensen 2014). For some, international migration decisions are based on often very local needs of who can take care of children or grandparents simultaneously, interdependently. From an interdependence perspective, mobility appears as a network that articulates the various productive and reproductive roles, routines and needs of a varying number of persons. These persons are related among themselves through essential emotional and/or practical links in the organisation of their daily lives, lives that are currently inconceivable without the existence of the other members of these networks (Jirón and Cortés 2011). Such intersections and interdependencies demand particular methodological attention.

\section{Methodologies for gender and generation}

Although the focus here is primarily on the entanglements of gendered and generational aspects of mobilities, studying these demands recognition that forms of mobilities are marked by relations of power and access that produce social differentiation in social, a key aspect of mobilities studies. These produce multiple forms of differentiation, unevenness and inequality. Hence we draw from the insights offered by intersectional studies of race, gender and class (Cho et al 2013; Valentine 2007) in understanding the ways in which gender and generation intersect in mobile space. The key contention here is that it is through attending to these in relation to questions of multiple forms of difference that the need for an intersectional analysis of inequality becomes visible. Walsh et al $(2013,261)$ argue that we need an 'array of research methods' to understand 'broad and inclusive perspectives on mobility'. In being attentive to the gendering and generationing of mobility there are a number of intersectional methodologies that can be called upon. Feminist methodologies (Maynard and Purvis 1994; Ramazanoglu and Holland 2002; Stanley and Wise 1993) are premised on the understanding that research should be grounded in women's experience. Studies in gendered mobilities (Priya Uteng and Cresswell 2008) tend to draw from such perspectives in, for example, considering the mobility cultures of mothering (Bostock 2001; Dowling 1999; Murray 2008). Feminist methodologies also call for a focus on the 'experiencing and feeling subject at the centre of all intellectual endeavour' (Stanley and Wise 1993, 193), on the embodied aspects of social experience. Sandoval's (2000) methodology of the oppressed also links well with differential mobilities, arguing for an attentiveness to the different conditions that are encountered in decision-making, and the need to make adjustments.

The spatiality of women's marginalization has been conceptualised in a number of ways and is often associated with the notions of risk and public and private space (Massey 1994; McDowell 1999; Pain 1997; Paul 2011; Sheller and Urry 2003; Valentine 1989). Gender and generation are associated, through mobilities, with particular embodied 
encounters and so methodologies for their understanding need also to take account of multisensory approaches: in anthropology (for example, Pink 2007); in mobile methodologies (Büscher et al. 2010; Fincham et al. 2010); in music and soundscape studies (Beer 2007; Thulin 2012). Particular methods, such as audio-visual methods (including audio-and visual recording) facilitate the exploration of mobile emotions. This is of course dependent on another key element: the recognition of the subjectivity of the research process and the need to be reflexive in approach, appreciating the positionality of the researcher. The use of audio-visual methods is considered to complement feminist methodologies as a 'feminist practice of looking... acts to engage with and challenge conventional relationships of power associated with the gaze' (Kindon 2003, 143). Although the adoption of the methodological approach can mitigate some of the consequences of imbalances of power, it is the responsibility of the feminist researcher to address issues of power not only in the research process but in wider society, as this forms the basis of these approaches. For McDowell (1999), the term embodiment encompasses the fluidity and flexibility of the socially constructed nature of the body, which for women can be the root of their subordination. We therefore contend that in drawing attention to the politics of intersectionality, feminist methodologies can correspond to mobile methodologies to usefully reveal gendered and unequal mobilities through situated and embodied experience.

Despite considerations of time and temporality being integral to thinking in the mobilities field (Cresswell 2006; Sheller and Urry 2006; Urry 2007), much of the scholarship around mobile methodologies is premised on an assumption of a politicising of space, where space is often privileged over time. For Massey $(2005,9)$ space is not reliant on time but is processual, a product of connections and interrelations, a 'sphere of 'coexisting heterogeneity' and an entity that is 'never finished, never closed'. Recently there has been a call for a decoupling of time from space so that time is given precedence. For example the 'distinct methodological paradigm' (Thomson and McLeod 2015, 243) of qualitative longitudinal research (QLR) is premised on a 'greater time perspective'. Of course time is critical to mobilities. In a recent issue of Mobilities, Anderson (2015) outlines the ways in which jet lag disrupts the rhythms of time and space. Similarly in a paper on the conceptual arsenal of QLR, Julie McLeod uses the experience of jet lag to illustrate the notion of the 'untimely', the disjuncture of time from its normative linearity. Drawing from Armitage's (2015) notion of trans-temporality, McLeod advocates taking the 'long view', of time as a continuum rather than politically distributed into epochs or periods, which privilege particular narratives over others (see for example Wendy Brown 2001). Thomson adopts this temporal approach in particular in relation to gender and generation (see for example Thomson 2014). Of course there are examples of longitudinal research that uses mobile methods such as Ross et al. (2009) longitudinal study of everyday lives of group of children in care. A number of studies have also looked at the relations of time in the context of global mobilities. For example Vannini $(2014,116)$ observes that 'to slow down nowadays means to decelerate from an ever increasingly pervasive regime built around the logic of speed'. This 'pervasive regime' is predicated on global mobilities, on the mobilities of capitalism, which again, necessitates a multi-scalar analysis. This can mean slowing down to stillness (Bissell and Fuller 2011). At a global scale polarization according to speed has been considered in relation to the mobilities and immobilities of migration (Bylander (2014), where as Yeoh and Ramdas $(2014,1198)$ remind us 'mobility across borders is not necessarily empowering, whilst immobility is not inherently disempowering'. At a more local yet globally connected scale, it is useful here to look critically to examples such as Cittaslow, the 'slow city' movement (Miele 2008), which is based on slowing down the movement of food so that it remains localized, of high quality and environmentally sustainable. Although this began in a few cities and towns in Italy, it is now an international movement.

Space and time are, of course co-constituted (Massey 2005) but it is in relation to generational approaches to mobilities that the confluence of time and space is most evident. Generation is by definition temporal and is often understood through longitudinal approaches that adopt a linear concept of time and create false demographic categories. Simultaneously, it is often particular generations, of children and older people that are marginalised from the thirst for speed in everyday life, be this in needing extra time to cross at traffic lights or being positioned as either the pioneers or laggers in technological innovation. A transdisciplinary mobilities approach, one that is evident in much of the scholarship within the 'mobilities turn', is useful in unpacking the generational exigencies of mobilities as it brings together studies that are premised on a relational and political approach to age (Hopkins and Pain 2007; Schwanen and Páez 2010) and can thus make sense of the situated experiences of mobility according to generation. Mobile methodologies have been used in research that makes visible the mobile inequalities experienced by particular generations, such as children and older people: streets, for example, that are built to facilitate the movement of car traffic through urban space, lights at pedestrian crossings that are too short, and driving habits that ignore the presence of pedestrian crosswalks. These methods have also been able to detect mobility practices and spaces that allow for various opportunities to overcome mobile inequalities, in terms of possibilities of sense of independence 
and usefulness for the elder. Hence the speed (temporality) of mobility is at odds with the speed (temporality) of these generations. So we can draw here from social studies of childhood methodologies that acknowledge children as actors in social processes, as valid sources of knowledge and that children's agency can provide valuable input to research methodology (James et al. 1998). For Mayall (2000) a childhood studies epistemology is grounded on: viewing the child as a part of the social order; seeing children as a social group with its own power structures; setting children's learning and experience within the political arena that includes children, parents and the state; and children having their own agency. This is reflected in numerous research projects that question normative assumptions of children through mobilities (Barker 2011; Mikkelsen and Christensen 2009; Murray 2015b; Ross et al. 2009). And of course these methodological insights can similarly be applied, although critically, to research with older people. Although the mobile methodologies and methods employed in these studies provide rich data on the embodied experiences of children and older people, what is needed is more attention to the broader contexts in which these embodied mobilities are situated.

Scholarship around policy mobilities (McCann 2011) has begun to devise methods of analysis to comprehend these multi-scalar mobilities. Knowledge of urban policy is immersed and mobilised by global circuits and the way this knowledge is inserted and mobilised within these circuits is as relevant as the way they are spatialised and contextualised through diverse assemblages. In this sense, contemporary studies on urban geography, policy and economics have used the notion of policy mobility and mutation assemblage as a framework though which to analyse these geographies. This approach is characterised by a concern on actors, practices and representations that affect the (re)production, adoption and mobility of policy models and best practices through time and space (Temenos and McCann 2013). The literature on urban policy model circulation acknowledges the existence of different agendas, particularly linked to globalisation, scale, power which allow such circulation (England and Ward 2007; McCann 2011). It is relevant to advance in the empirical research on the contexts and practices of policy circulation its application to local spaces, the mutations, hybridities that emerge from these. In this sense, the mobility paradigm applied to urban policy model circulation opens up an important field of research, on how these policies reach local arenas, how they are installed adapted and the consequences thereof. This is crucial in order to comprehend daily spatial experiences, as well as practices of urban intervention that feed the circulation of policy models. It implies that understanding urban practices as situated, and acknowledging the ways in which this knowledge comes to being is multi-sited, is fundamental.

\section{Mediating street space by gender and generation}

The methodologies described above underpin our comparative analysis of the gendering and generationing of urban street space. The 'mobile' part of cities, its streets and pavements (sidewalks) can be particularly contested, and marginalizing spaces where street design can be enabling or disabling for those who move at different velocitiesincluding those who are older or younger. Increasingly, these spaces are negotiated digitally: they are at the interface of the materialities of the built environment, communication technologies, and the bodies who use those devices. Hence our study explored the confluence of media practices in the summertime (for 2) and the winter (for 1): Brighton (UK), Montreal and Santiago (Chile) that incorporate design features aimed at enhancing city experiences for people with a range of social characteristics. Adopting a comparative mobilities approach, our focus was on understanding the generational and gendered interactions within these spaces. The focus of the ethnography was a 'bench study' previously piloted in a study of 'shared space' in Brighton (Murray and Robertson, forthcoming). This involves capturing movement in and around a particular bench and talking to people on or near the bench. In deciding to examine three sites we looked for street spaces that: had been 'designed' through urban interventions that sought to improve the liveability of the space; are both mobile and transient (Jirón 2010; Jirón and Iturra 2012) in that the streets are fleetingly occupied by cars, cycles and pedestrians; have designated places to dwell including benches; are socially and culturally diverse; and are 'open' 24 hours a day. The study explored how digital practices produce movement and flows through city spaces and how these are differentiated according to gender and generation. Premised on understanding the negotiation of visible and invisible difference in mobile spaces of the city, we used mobile and reflective interviews, video, and photography to collect data on the social interactions within the space over a two-day period in each city in June and July 2015. 
The focal point of comparison here, the 'bench', is ubiquitous yet situated. It is 'open' to social difference and flexible in function. The 'bench study' method focused the ethnographical research on particular benches in each of the public mobile spaces, benches that we had previously observed are the hub of activity in each of the sites. The bench here is an illuminator of mobile lives, in acknowledging the settlement or relative immobility, as well as movement (Murray and Robertson, forthcoming). This comparative method thus illuminates the ways in which people of different generations and gender may be marginalised from public space, focusing on a place in which the pace of mobility is slowed or stopped but in which there is rarely a stillness as people interact with the space around them or with more distant people and things through communications technologies or music. The bench is also both nation-specific and global in that it constituted from materials from near and far, from wood sourced from local forests or from concrete or metals, fixed or mobile. It is located in local politics and cultures, it may be designed according to national guidelines and commissioned by opposing local authorities and used by rough sleepers or denied to homeless people by virtue of its design. Our benches, in each city were observed, interactions were audiovisually recorded and people on the bench were interviewed. People were sitting and pausing, they were to some extent 'still' but there was never a sense of complete quietude. Like the idea of liveliness what we see as 'still water' gives rise to a plethora of activity, even if it is not immediately perceptible. Our observation of 'still' was more appropriately associated with 'continuation' and in particular a gendered and generational continuation in which the urban spaces were enabling. Users of the spaces were 'still' able. The focus on the mobile space of the bench rather than the more usual mobile spaces of the street made visible marginalization according to gender and generation but often this marginalization was appropriated by those who are most often marginalised. In our spaces, that incorporated slowness as well as speed, many adopted communication technological devices - cell phones made from materials mined in Africa and assembled in China- to speak to family members at the nearby market where food produced locally sits alongside of vegetables and fruits that are imported: or music from Korea to dance to in Santiago. But they also chose to turn off their mobile devices to occupy the city spaces and to interact with people and objects either directly or indirectly. For a number of years the ways in which we come to understand these entangled, interdependent and multi-scalar mobilities has been the subject of much debate.

\section{Travelling methodologies}

The setting out of the comparative study above raises questions about the ways in which experiences according to gender and generation can begin to be framed within broader socio-cultural, political and temporal contexts through comparative mobilities. Adopting methodologies that travel is a prerequisite for comparative research - whether this is travelling in time or traveling in space. However, of course, not all methods travel and nor do they need to, as methods can be adapted to local circumstances and cultures. Hantrais (2009) provides a comprehensive overview of comparative studies with particular attention to international comparisons. She argues that the term 'International Comparative Research' rather than cross-national/cultural allows emphasis on the relationship between social phenomena being investigated and the characteristics of the country that may produce these phenomena in a particular way. Robinson (2013) is critical of such an approach and instead calls for ways of overcoming hegemonic colonialism and parochialism, which tend to further urban theory based on the comparison of particular cities. In her postcolonial critique she instead argues that we need to push further, and start producing urban theory for a globalised world. Her criticism on traditional comparative international studies particularly on global cities calls for a new experimental approach to comparativism, based on specific processes, urban elements or even connection between cities rather than territorial entities (Robinson 2013). Robinson $(2011,19)$ uses the idea of experimental comparativism as a way of enabling 'urban studies to stretch its resources for theory building across the world of cities'. In this research, in keeping with this critical approach, the emphasis is on comparing more 'ordinary' (Jacobs 2012) cities. In a mobilities context that is multi-scalar and appreciates both the relevance of the national as well as networks and flows that operate beyond nation states, an experimental comparative mobilities approach should be both international and transnational. Rather than producing a series of discrete and nation-specific outcomes, such a comparison aims to produce a set of outcomes that both transcend the countries being studied but at the same time takes account of local and national politics and cultures.

Hence, drawing out the distinctions as well as the similarities in the design of mobile spaces in space and time are paid due attention in our research. This is particular critical in taking account of the histories that imbue cultural understanding of the spaces. Embodied experience of the bench in each of our cities is dependent on factors 
including memory. This will be dependent on the histories of the spaces as well as previous encounters with the spaces. For example, both Shamrock Place and Jubilee Square are spaces of contemporary urban design, based on the trends of 'placemaking' and urban public art. Jubilee Square was developed from a derelict inner city site, most recently a car park, through a Private Finance Initiative between Brighton and Hove Council and a development company, and continues to be managed as a private space, despite appearing to be 'public'. Shamrock Place, with a long history in the city of Montreal, was revitalized in 2013 at the instigation of local shopkeepers on St Laurent Boulevard, wanting to provide a means of enticing consumers from the very popular Jean-Talon Market to their street. In contrast, GAM was built during the Allende government in Chile, in the year before the military coup of 1973 , as a centre of cultural activity. GAM was built collaboratively by architects, artists, constructions workers, creating in a very short period a new way of seeing society. The various transformations the building underwent during dictatorship and afterwards, paved the way to make this one of the most welcoming public spaces in Santiago today. The building still captures some of the original spaces along with contemporary design ideas.

The significance of digital technologies, and the use of new forms of mobile media for social coordination is another important aspect of comparison that incorporates both space and time. Here we understand digital data as 'alive', embodied and mobile' (Ruppert et al. 2013, 22). As Ruppert et al. argue, digital technologies themselves are, not only productive of knowledge of social change but implicated in social change and need to be understood as heterogeneous, with context specific practices and meanings related to generation and gender, rather than devices with fixed characteristics throughout space and time. A comparative mobilities approach therefore recognises that 'being there' may mean taking into account the ways that spatial and temporal contexts - including differences - may be revealed through comparative reflections. This type of comparative reflection requires telescopic thinking: looking across time beyond mere periodisation, to the ways that temporalities are experienced; looking across space in relation to other spaces, including the situatedness of the researchers. We argue that, although much if not all of the research carried out in mobilities is comparative, there is less attention given to an overt thinking through of how we may more systematically and consciously begin to engage in methodologies of comparison: and how such attentiveness may indeed shift our own interest in gender, generation, and inter-and intra-generational practices of mobilities, including the use of new forms of networked connection for the organization and experience of movements through spaces, such as the micro-coordination of daily routines and tasks. What possibilities or outcomes may be overlooked? In some cases there has been critique of lack of attention to cultural specificities as a result of certain quantitative methodologies adopted (Mikkelsen and Christensen 2009, Murray 2015b).

\section{Conclusion}

Our comparative mobilities approach thus makes two key contributions to mobile methodologies. Firstly, it acknowledges the importance of situated knowledge based on the complex relationships between, bodies, technologies, design and spaces. Mobile space is imbued with political and cultural meaning according to intersecting social differences that is contingent on multiple spatial scales from local, to city to nation to global. As Manderschied $(2009,32)$ highlights there are calls within the mobilities field to move beyond nation states in that there exists a 'multiplicity of spaces... [that] are not congruent with set territorial units such as urban neighbourhoods, cities, regions or countries. However, she also points out that inequalities are socio-culturally embedded. Our situated knowledge therefore takes account of unequal mobilities, which here is viewed through the lens of gender and generation. It adopts an approach to urban formations that draws from scholars such as McCann and Ward (2010) who argue that urban development takes place in the context of local globalness and cities are both relational and territorial. Secondly, our approach encapsulates the notion of 'boundary objects' (Star 1989, 2010) or 'territorial edges' (Sennett 2006) in order to both reveal inequalities of gender and generation and also the ways in which spaces are open to difference. Here, the border or edge is the urban bench, a mutable object that allows different social groups to work together without consensus. In each of our cities, the disposition, location and materiality of the benches generate a sort of flexible space, where different people can be accommodated as they please. Hence the bench affords interdependent relations - both gendered and generational - as our opening paragraph illuminates.

This paper represents the beginnings of a methodological approach, which is guided by current debates and methodological experimentation, and is attentive to a mobile world that is unequal. We draw from feminist epistemologies in understanding the subjugation of people according to social difference. We overlap these 
methodological approaches with methodologies developed in researching with children and gerontological studies in understanding the situatedness of knowledge. This knowledge is situated according to difference and the ways in which intersections of social difference are produced at different spatial and temporal scales. Our methods were experimental and alive but acknowledged approached to technological change that may be tied to a complex confluence of generational experiences. We hence used methods of comparative research, which acknowledged existing inequalities and allowed us to compare at different scales. Thus the bench study, as a means of focusing on a material object seeped in the culture and politics at different scales took into account the idea that mobilities research also means a consideration of slowing though not stoppage or linking between spaces and speeds. The bench is a key technology for the study of generational and intergenerational interactions. Together, from these different vantage points, we will develop a comparative strategy providing a material focus for data collection and an object that travels well across times and spaces. There is much more to be done with the huge amount of data collected but it holds great promise in allowing us to look at scalar interconnections and gendered and generational mobilities that are and are not nation-specific.

\section{Acknowledgements}

We wish to acknowledge the support of the Social Sciences and Humanities research Council Canada in funding the comparative study: Mediated street spaces: intergenerational interactions, technologies and design. The funding was made available through the Ageing and Communication Technologies (ACT) International Partnership. 


\section{References}

Akyelken, N. 2013. "Development and Gendered Mobilities: Narratives from the Women of Mardin, Turkey." Mobilities 8:3: 424-439

Anderson, J. 2015 "Exploring the Consequences of Mobility: Reclaiming Jet Lag as the State of Travel Disorientation." Mobilities 10 (1): 1-16

Armitage, M. (2105) "Horizons of History: Space, Time and the Future of the Past.” History Australia 12(1): 207-225.

Barker, J. 2011. “'Manic Mums' and 'Distant Dads'? Gendered Geographies of Care and the Journey to

School." Health and Place 17 (2): 413 -421.

Beer, D. 2007. “Tune Out: Music, Soundscapes and the Urban Mise-en-scene.” Information, Communication \& Society 10 (6): 846-866.

Bissell, D., Fuller, G. 2011. Stillness Unbound. In Bissell, D., Fuller, G. (Eds.) Stillness in a Mobile World (Abingdon, Oxon, UK: Routledge).

Bostock, L. 2001, "Pathways of Disadvantage? Walking as a Mode of Transport Among Low-income Mothers." Health and Social Care in the Community 9(1): 11-18.

Büscher, M., Urry, J. and Witchger, K. 2010. Mobile methods. London: Routledge.

Cho, S., Williams Crenshaw, K. and McCall, L. 2013. "Toward a Field of Intersectionality Studies: Theory, Applications, and Praxis." Signs 38 (4): 785-810.

Cortés-Morales, S and Christensen, P. 2014. Unfolding the Pushchair. Children's Mobilities and Everyday Technologies, REM - Research on education and media 6 (2): 9-18.

Cresswell, T. 2006. On the move. New York: Routledge.

Crow, B. and Sawchuk, K. 2012 “'I'm G-Mom on the Phone': Remote Grandmothering, Cell Phones and Inter/generational Dis/connections." Feminist Media Studies 12 (4): 475-489.

Dowling, R. 1999. "Cultures of Mothering and Car use in Suburban Sydney: a Preliminary Investigation." Geoforum 31: 345-353.

England K. and Ward K. ed. 2007. Neoliberalization: States, Networks, Peoples. Oxford: Blackwell

Gutiérrez, A. 2011. "Informe Movilidad y Salud Materna de Adolescentes en el Periurbano Bonaerense. Un Caso Modelo para Estudiar Problemas de Acceso en Forma Intersectorial." Programa de Transporte y Territorio Instituto de Geografia "Romualdo Ardissone" Facultad de Filosofía y Letras, Universidad de Buenos Aires.

Handrais, L. 2009. International Comparative Research Theory, Methods and Practice London: Palgrave Macmillan

Hopkins, P. and Pain R. 2007. Geographies of age: thinking relationally. Area. 39 (3): 287-294.

Jacobs, J. 2012. “Urban Geographies I: Still Thinking Cities Relationally.” Progress in Human Geography. 36: 412.

James, A., Jenks, C., Prout, A., 1998. Theorizing Childhood. Polity Press, Cambridge.

Jiron P. and Cortes, S. 2011. "Mobile relations, mobile shadows. Understanding contemporary urban daily living through shadowing techniques" Paper presented at International Workshop: The Everyday Life of Multi-Local Families. Concepts, Methods and the Example of Post-Separation Families, October 20-21 2011, Munich, Alemania

Jirón, P. and Imilan, W. 2014. "Embodying Flexibility: Experiencing Labour Flexibility through Urban Daily Mobility in Santiago de Chile." Mobilities 10 (1): 119-135.

Jirón, P. and Iturra, L. 2014. “Travelling the Journey. Understanding Mobility Trajectories by Recreating Research Paths”. In Murray, L. and Upstone, S. Researching and Representing mobilities: transdisciplinary encounters.

Kindon, S. 2003. "Participatory Video in Geographic Research: a Feminist Practice of Looking?" Area 35: 42-153.

Manderscheid, K. 2009. “Unequal Mobilities.” In Ohnmacht, T., Maksim, H and Bergman, M. eds. Mobilities and inequality. London: Ashgate. 
Massey, D. 2005. For Space. London: Sage.

Massey, D. 1994, Space, Place and Gender. Cambridge: Polity Press.

Maynard, M. and Purvis, J. eds. 1994. Researching Women's Lives from a Feminist Perspective. London: Taylor and Francis.

McCann E. and Ward, K. 2011. Mobile urbanisms: cities and Policymaking in the Global Age, Minneapolis-London: University of Minnesota:

McCann, E. and Ward, K. 2010. "Relationality/Territoriality: Toward a Conceptualization of Cities in the World." Geoforum 41: 175-184.

Mayall, B. 2000. "Conversations with Children, Working with Generational Issues." In Christensen, P. and James, A. (eds.) Research with children. London: Falmer Press.

McDowell, L. 1999. Gender, Identity and Place: Understanding Feminist Geographies. Cambridge: Polity Press.

Mikkelsen, M. R. and Christensen, P. 2009. "Is Children's independent mobility really independent? A study of children's mobility combining ethnography and GPS/mobile phone technologies." Mobilities 4 (1): 37-58.

Miele, M. 2008. “Cittaslow: Producing Slow Cities Against the Fast Life.” Space and Polity 12 (1): 135-156.

Murray, L. 2015a. “Age-friendly Mobilities: a Transdisciplinary and Intergenerational Perspective." Journal of Transport and health 2 (2): 302-307.

Murray, L. 2015b. “Rethinking Children's Independent Mobility and Revealing Cultures of Children's Agentic and Imaginative Mobilities through 'Emil and the detectives"'. Transfers: Interdisciplinary Journal of Mobility Studies 5 (1): 2845

Murray, L. 2009. “Looking at and Looking Back: Visualization in Mobile Research.” Qualitative Research 9 (4): 469488.

Murray, L. 2008. "Motherhood, Risk and Everyday Mobilities”. In Priya Uteng, T. and Cresswell, T. (eds.) Gendered mobilities. Aldershot, Hampshire: Ashgate

Murray, L. and Robertson, S. (forthcoming). Drawing Mobile Shared Spaces. In Reimer, S., Pinch, P. and Spinney, J. Mobilising design. London: Routledge.

Pain, R. 1997, "Social Geographies of Women's Fear of Crime." Transactions of the British Geographical Society 22: 231244.

Paul, T. 2011. "Space, Gender and Fear of Crime: some Explorations from Kolkata." Gender, Technology and Development 15 (3): 411-35.

Pink, S. 2007. Doing Visual Ethnography: Images, Media and Representation in Research. Revised and expanded $2^{\text {nd }}$ edition. London: Sage.

Priya Uteng, T. and Cresswell, T. 2008. Gendered mobilities, Aldershot, Hampshire, Ashgate.

Ramazanoglu, C. and Holland, J. 2002. Feminist Methodology: Challenges and Choices. London: Sage.

Robinson, J. 2011. 'The Space of Circulating Knowledge: City Strategies and Global Urban Governmentality', [in:] McCann, E. and K. Ward (eds.), Mobile Urbanism. Cities and Policymaking in the Global Age, Minneapolis-London: University of Minnesota Press, pp. 15-40.

Robinson, J. 2013. "The Urban Now: Theorising Cities Beyond the New” European Journal of Cultural Studies,16: 659-677

Ross, N., Renold, E., Holland, S., Hillman, A. 2009. "Moving Stories: Using Mobile Methods to Explore the Everyday Lives of Young People in Public Care." Qualitative Research 9 (5): 605-623

Ruppert, E., Law, J., and Savage, M. (2013). "Reassembling Social Science Methods: The Challenge of Digital Devices.” Theory, Culture \& Society 30: 22-46.

Sandoval, C. 2000. Methodology of the Oppressed. Book Series: Theory Out of Bounds. University of Minnesota Press.

Schwanen, T. and Páez, A. 2010. "The mobility of older people - an introduction." Journal of Transport Geography 18 (5): 591-595. 
Sennett, R. 2006. The open city, Newspaper essay, Urban Age, London: London School of Economics. Accessed at: http://downloads.lsecities.net/0_downloads/Berlin_Richard_Sennett_2006-The_Open_City.pdf on 13 July 2015.

Sheller, M. and J. Urry. 2006. “The New Mobilities Paradigm.” Environment and planning A 38: 207-226.

Sheller, M., \& Urry, J. 2003, "Mobile Transformations of 'Public' and 'Private' Life." Theory, culture and society 20(3): 107-125.

Stanley, L. and S. Wise. 1993. Breaking Out Again. London: Routledge.

Star, S. \& Griesemer, J. 1989 “Institutional Ecology, 'Translations' and Boundary Objects: Amateurs and Professionals in Berkeley's Museum of Vertebrate Zoology 1907-39." Social Studies of Science 19 (3): 387-420

Star, S. 2010 "This is Not a Boundary Object: Reflections on the Origin of a Concept." Science Tecbnology Human Values. 35 (5): 601-617.

Thomson, R. 2014. "Generational Research: Between Historical and Sociological Imaginations." International Journal of Social Research Methodology 17 (2): 147-156.

Thomson, R. and McLeod, J. 2015. "New frontiers in qualitative longitudinal research: an agenda for research." International Journal of Social Research Methodology 18 (3). pp. 243-250.

Thulin, S. 2012. "Mobile Audio Apps, Place and Life Beyond Immersive Interactivity". Wi: Journal of Mobile Media. 6: 3

Urry, J. 2007. Mobilities. London: Routledge.

Valentine, G. 1989, “The Geography of Women's Fear.” Area 21: 385-390.

Valentine, G. 2007. "Theorizing and Researching Intersectionality: A Challenge for Feminist Geography." The Professional Geographer 59 (1): 10-21.

Vannini, P. 2014. “Slowness and deceleration.” In Adey, P., Bissell, D., Hannam, K., Merriman, P. and Sheller, M. (eds.) The Routledge Handbook of Mobilities. London: Routledge.

Walsh, D. Valestrand, H. Gerrard, S. and Aure, M. 2013. "Gendered Mobilities in the North: Advancing an International Comparative Perspective.” Norsk Geografisk. Tidsskrift - Norwegian Journal of Geography 67 (5): 260-265.

Yeoh, B. and Ramdas, K. 2014. "Gender, migration, mobility and transnationalism”, Gender, Place \& Culture 21 (10): 1197-1213.

Ziegler, F. and Schwanen, T. 2011. 'I Like to Go Out to be Energised by Different People': an Exploratory Analysis of Mobility and Wellbeing in Later Life. Ageing and Society 31: 758-781 